\title{
LA RESPONSABILIDAD POR FALTA DE SERVICIO EN LA ADMINISTRACIÓN HOSPITALARIA EN LA JURISPRUDENCIA CHILENA
}

\author{
ADMINISTRATIVE FAULT LIABILITY OF PUBLIC HOSPITALS IN \\ CHILEAN JURISPRUDENCE
}

JOSÉ MIGUEL VALDIVIA OLIVARES*

\section{RESUMEN}

Desde 2004 el derecho chileno cuenta con legislación especial aplicable a la responsabilidad del Estado originada en el desempeño de los organismos públicos en el campo sanitario, extendiendo al terreno hospitalario el sistema de la responsabilidad por falta de servicio. Este trabajo intenta una categorización de los casos que se presentan en la materia, tomando en cuenta las especificidades de la actividad hospitalaria pública.

Palabras Clave: Responsabilidad del Estado; hospitales públicos; negligencia; falta de servicio; culpa probada; perjuicios.

\section{ABSTRACT}

Since 2004, Chilean law has a special statute on State liability relating to the field of health's services; thus, the regime of the State fault is extended

\footnotetext{
*Abogado, Licenciado en derecho, Universidad de Chile. Doctor en derecho por la Universidad Paris II, Panthéon-Assas. Profesor de Derecho Administrativo. Correo electrónico: jmvaldivia@derecho. uchile.cl. ORCID ID: 0000-0002-7556-2951.
}

Artículo recibido el 8 de julio de 2019 y aceptado para su publicación el 20 de noviembre de 2019. 
to public hospitals. This work tries a categorization of cases arising in this filed, given the specificities of the public hospital missions.

Keywords: State liability; public hospitals; malpractice; lack of service (strict liability); proven negligence; damages.

\section{INTRODUCCIÓN}

Desde 2004 el derecho chileno cuenta con reglas específicamente aplicables a la responsabilidad extracontractual del Estado originada en el desempeño de los organismos públicos en el campo sanitario. Este régimen proyecta al terreno hospitalario el sistema de la responsabilidad por falta de servicio, que impera con carácter general sobre otros sectores de la administración del Estado.

Sin duda, la responsabilidad plantea cuestiones de extrema importancia en materia médica y hospitalaria, en razón de las consecuencias fisiológicas que a menudo importa el daño y -atendida la condición del paciente al tiempo de ingresar al hospital- también de la complejidad de la relación de causalidad. Sin embargo, a pesar de algunas reglas especiales, ${ }^{1}$ rigen aquí las orientaciones generales del derecho de la responsabilidad civil. ${ }^{2}$ En cambio, el factor que aparece como propiamente distintivo del sistema desde la perspectiva del derecho público es la noción de falta de servicio (cuyo antecedente se sitúa en el derecho administrativo francés de la responsabilidad pública). ${ }^{3}$

${ }^{1}$ El artículo 41 de la Ley $N^{\circ}$ 19.966, 2004, dispone: "La indemnización por el daño moral será fijada por el juez considerando la gravedad del daño y la modificación de las condiciones de existencia del afectado con el daño producido, atendiendo su edad y condiciones físicas./ No serán indemnizables los daños que se deriven de hechos o circunstancias que no se hubieran podido prever o evitar según el estado de los conocimientos de la ciencia o de la técnica existentes en el momento de producirse aquéllos". Un breve análisis del precepto en Pizarro Wilson, Carlos, "Controversias jurisprudenciales de la responsabilidad de los servicios públicos de salud", Cuadernos de Análisis Jurídico, 2007, $\mathrm{N}^{\circ} 6$, p. 187 y ss. Adviértase que el inciso segundo proviene del derecho español, que hoy recoge una disposición análoga en el artículo 34.1 de la Ley 40-2015 de Régimen Jurídico del Sector Público.

2 Así ocurre, respecto de la responsabilidad del Estado en general, según BArros BourIE, Enrique, Tratado de responsabilidad extracontractual, Editorial Jurídica, Santiago, 2006, p. 501 y ss.

${ }^{3}$ La filiación francesa del sistema chileno de responsabilidad pública está acreditada desde los orígenes de la Ley N 18.575, 1986; cfr. Informe de la Cuarta Comisión Legislativa de 27 de junio de 1986, en "Historia de la Ley 18.575", archivo pdf, disponible en línea: https://www.bcn.cl/historiadelaley/nc/ historia-de-la-ley/7579/ (fecha de visita: 16 de mayo de 2019), pp. 175-176. 
El tratamiento científico de la materia ha sido conducido, con pocas excepciones, ${ }^{4}$ por especialistas del derecho privado, ${ }^{5}$ como si la responsabilidad hospitalaria pública formase parte de la responsabilidad extracontractual en general. ${ }^{6}$ Sin duda, a la hora de juzgar la consistencia del derecho no puede desconocerse la pertinencia de un enfoque comparativo entre el derecho privado y el derecho público de la responsabilidad. Con todo, cabe temer que una mirada "privatista" de esta materia invisibilice algunas especificidades propias de las misiones del hospital público, o al menos de su organización. A fin de cuentas, un hospital es un servicio público, noción que tradicionalmente ha implicado sometimiento a un régimen de derecho público. $^{7}$

El presente estudio se propone organizar las principales categorías de casos que se presentan en la práctica en este terreno. Por la índole de su objeto, la investigación se construye fundamentalmente a partir de la jurisprudencia. ${ }^{8}$ El estudio ha sido guiado bajo la hipótesis de que en la materia la jurisprudencia aplica de modo ortodoxo un régimen de falta de servicio, adaptado - sin embargo- a las singularidades de la salud pública. Esas singularidades están marcadas, ante todo, por la importancia de la medicina en las prestaciones que se imparten en establecimientos hospitalarios. Al mismo tiempo, el carácter público del establecimiento hospitalario imprime notas particulares a la responsabilidad, aunque sea por la consideración orgánica del hospital como servicio público.

En la estructura del trabajo, los desarrollos más significativos, que proponen una clasificación de los casos, se contienen en la segunda parte.

\footnotetext{
${ }^{4}$ Para un enfoque sobre la responsabilidad hospitalaria desde el punto de vista del derecho público, v. Huepe Artigas, Fabián, "La falta de servicio en la responsabilidad sanitaria", en: Letelier, R. (coord.), La falta de servicio, Legal Publishing, Santiago, 2012, p. 134 y ss.

5 El principal estudio monográfico es Cárdenas Villarreal, Hugo; Moreno Molinet, Jaime, Responsabilidad médica. Estándares jurisprudenciales de la falta de servicio, Legal Publishing, Santiago, 2011. Cfr. también Pizarro Wilson, Carlos, La responsabilidad civil médica, Thomson Reuters, Santiago, 2017.

6 Examinando en conjunto la responsabilidad hospitalaria pública y privada, TOCORNAL CoOPER, Josefina, La responsabilidad de clínicas y hospitales, Legal Publishing, Santiago, 2014.

7 V. en general, Silva Cimma, Enrique, Derecho administrativo chileno y comparado, T. IV (El servicio público), Editorial Jurídica, Santiago, 1995, p. $72 \mathrm{~s}$.

8 Por lo esencial, el estudio se centra en la jurisprudencia de la Corte Suprema de los años 2016 y 2017, respecto de la responsabilidad de los servicios de salud, a la cual se han agregado algunos pronunciamientos posteriores que han confirmado las líneas jurisprudenciales detectadas. Sin embargo, también se ha recurrido a elementos jurisprudenciales más antiguos, con el fin de resaltar la consistencia temporal de las soluciones actuales.
} 
Previamente, parece necesario dar cuenta de los rasgos principales del sistema de responsabilidad por falta de servicio en materia sanitaria.

\section{EL RÉGIMEN LEGAL}

La Ley N¹9.966, de 2004, que establece un Régimen de Garantías en Salud, instituyó un sistema particular de responsabilidad por falta de servicio, cuyo precepto central reza:

Los órganos de la Administración del Estado en materia sanitaria serán responsables de los daños que causen a particulares por falta de servicio (artículo 38, inciso 1).

Habida cuenta de que el régimen general de responsabilidad del Estado, ${ }^{9}$ contenido en la Ley $\mathrm{N}^{\circ} 18.575$, de Bases Generales de la Administración del Estado, también es un régimen de responsabilidad por falta de servicio, sólo cabe concluir que la ley de 2004 tiene carácter especial. Para aprehender los contornos de este sistema conviene delimitar bien su ámbito de aplicación $\mathrm{y}$, en seguida, sus singularidades sustantivas.

\section{1. Ámbito de aplicación del régimen legal}

El régimen previsto por la ley se aplica ante todo a los hospitales integrantes de la red asistencial pública de salud, que en términos organizativos forman parte de los denominados servicios de salud. Sin embargo, la ley de 2004 tuvo la pretensión de abordar, en términos funcionales, a todo organismo administrativo que intervenga en materia sanitaria.

Los servicios de salud son instituciones administrativas especializadas, cuya misión -en términos generales- es ejecutar las políticas de salud pública en el ámbito asistencial. En otras palabras, la administración de los hospitales públicos es su función más significativa, ${ }^{10}$

9 Existe alguna discusión sobre el carácter general del régimen desde una perspectiva normativa; cfr. Sото KLoss, Eduardo, "Falta de servicio ¿Régimen general de la responsabilidad del Estado/ Administración en Chile? (El derecho ¿arte de magia?)", en Universidad Santo Tomás (eds.), La responsabilidad del Estado-Administración. Conferencias Santo Tomás de Aquino 2006, Ed. Andros, Santiago, 2006, pp. 117 y ss. Con todo, en los hechos la responsabilidad por falta de servicio opera sin contrapesos como régimen general de responsabilidad pública.

${ }^{10}$ En general, esta función está concebida como la gestión “de la red asistencial correspondiente, para la 
y probablemente también la más visible. ${ }^{11}$ Estos servicios públicos cuentan con personalidad y patrimonio propios, es decir, son organismos administrativos descentralizados. ${ }^{12}$ Por eso, históricamente han sido ellos quienes han debido soportar el impacto pecuniario de la (mala) gestión de los hospitales públicos.

Ahora bien, la llamada Ley de Autoridad Sanitaria introdujo reglas que han suscitado innecesarias vacilaciones jurisprudenciales, en relación con la condición procesal de los hospitales calificados como "establecimientos autogestionados en red" (que hoy en día son prácticamente todos los hospitales públicos). ${ }^{13}$ Aunque estos establecimientos carecen de personalidad jurídica, ${ }^{14}$ cuentan con cierta autonomía judicial con respecto al servicio de salud que integran: la ley prevé que la representación judicial del servicio de salud se entenderá "delegada" en el director del hospital. ${ }^{15}$ Tras mucha vacilación, la jurisprudencia parece orientarse en la dirección correcta, entendiendo que en los juicios de responsabilidad la legitimación

ejecución de las acciones integradas de fomento, protección y recuperación de la salud y rehabilitación de las personas enfermas”. Decreto Ley N²763, 2006, artículo 16.

${ }^{11}$ Por un tiempo los servicios de salud contaron con atribuciones adicionales a la gestión hospitalaria, consistentes en el control sanitario de otras actividades. También imperaba en la materia una responsabilidad por culpa; p. ej., Corte Suprema, 31 de mayo de 2007, Rol N³174-2005: responsabilidad por falta de servicio del Servicio de Salud de Arica por desidia frente al acopio de desechos metálicos peligrosos para la salud de las personas, a proximidad inmediata de centros poblados; cfr. VALDIVIA Olivares, José Miguel, “Por qué es importante el fallo ‘Promel’ para el derecho público?”, Justicia Ambiental, 2009, $\mathrm{N}^{\circ} 1$, pp. 279 y ss. Para el Servicio Nacional de Salud, antecesor de los Servicios de salud, v. Corte Suprema, 10 de octubre de 1991, Rol N4944-1991: responsabilidad acogida sobre el fundamento de la noción civil de culpa. La Ley $\mathrm{N}^{\circ} 19.937,2004$, sustrajo a los servicios de salud algunas de sus antiguas funciones, radicando en ellos únicamente la ejecución de las prestaciones sanitarias (tal como consta en el artículo 16 del Decreto Ley N²763, 2006 modificado por esa ley).

${ }^{12}$ Luego, el Estado no responde por ellos: Corte Suprema, 6 de septiembre de 2016, Rol N²0.5192016. Además, como son instituciones distintas del Fisco, los procesos en su contra se rigen por las normas generales y no por las reglas especiales del "juicio de hacienda": Corte de Apelaciones de La Serena, 22 de noviembre de 1989, Rol N629. Por último, asumen por su cuenta su representación judicial, a menos que obtengan puntualmente que el Consejo de Defensa del Estado asuma su defensa en juicio (Decreto con Fuerza de Ley $\mathrm{N}^{\circ} 1,1993$, artículo $3 \mathrm{~N}^{\circ} 3$ ).

${ }^{13}$ Ley $\mathrm{N}^{\circ} 19.937,2004$, artículo 15 transitorio.

${ }^{14}$ Pero sí gozan de una especie de patrimonio de afectación, pues en el ejercicio de sus atribuciones, "no comprometerán sino los recursos y bienes afectos al cumplimiento de sus fines propios", Decreto con Fuerza de Ley $\mathrm{N}^{\circ} 1,1993$, artículo 31, inciso 6.

${ }^{15}$ Decreto con Fuerza de Ley $N^{\circ} 1,1993$, artículo 36, inciso final: "Para todos los efectos legales, la representación judicial y extrajudicial del Servicio de Salud respectivo se entenderá delegada en el Director del Establecimiento, cuando ejerza las atribuciones señaladas en este artículo. Notificada la demanda, deberá ponerla, en el plazo de 48 horas, en conocimiento personal del Director del Servicio de Salud correspondiente, quien deberá adoptar las medidas administrativas que procedieran y podrá intervenir como coadyuvante en cualquier estado del juicio". 
pasiva recae (en cuanto sujeto de derecho demandado) en el servicio de salud, aunque deba emplazarse al director del hospital autogestionado de que se trate. ${ }^{16}$

Los servicios de salud estaban sujetos al régimen general de responsabilidad por falta de servicio desde antes de la ley de 2004. Ahora bien, ésta extiende el sistema de la falta de servicio de modo genérico a (todos) los "órganos de la Administración del Estado en materia sanitaria". Así, en cuanto a la responsabilidad civil, los problemas derivados de la medicina pública no pueden analizarse atendiendo únicamente a los servicios de salud.

En efecto, además de los hospitales de la red asistencial estatal, cumplen funciones similares, o estrechamente vinculadas con ellos, los hospitales del orden militar (relacionados, organizativa y funcionalmente, con las instituciones castrenses o policiales) y otros establecimientos hospitalarios públicos, como los pertenecientes a instituciones especializadas (los hospitales universitarios, por ejemplo), los establecimientos de la red primaria, compuestos básicamente por consultorios municipales y, por último, otros servicios públicos que ocasional o permanentemente disponen de unidades funcionales encargadas de prestar servicios sanitarios (típicamente, las cárceles). ${ }^{17}$ Aunque hasta ahora no hay definición jurisprudencial explícita de lo que deba entenderse por materia sanitaria,${ }^{18}$ no debería ser dudoso que estas otras instituciones están sujetas, al igual que los servicios de salud, a las disposiciones de la Ley 19.966. ${ }^{19}$ La confirmación de este razonamiento parece venir dada por un reciente fallo Vera Ordenes, en que a propósito de

\footnotetext{
${ }^{16}$ Para la buena doctrina, v. CÁrdenas Villarroel, Hugo, "La legitimación pasiva de la administración médico sanitaria en la era de los establecimientos autogestionados en red", Revista Chilena de Derecho, 2018, Vol. 45, N², pp. 479 y ss.

${ }^{17}$ Para una visión panorámica de las distintas instituciones públicas que participan de la función hospitalaria, CÁRdenAS y MoReno, cit. (n. 4), p. 13 y ss.

${ }^{18}$ El mismo cuerpo legal que introdujo esta fórmula "órganos del Estado en materia sanitaria" identifica el perímetro de la red asistencial de los servicios de salud, como integrado "por el conjunto de establecimientos asistenciales públicos que forman parte del Servicio, los establecimientos municipales de atención primaria de salud de su territorio y los demás establecimientos públicos o privados que suscriban convenio con el Servicio de Salud respectivo" (Decreto con Fuerza de Ley $\mathrm{N}^{\circ} 1,1993$, artículo 17).

${ }^{19}$ La práctica sugiere que en este ámbito entran en juego muchos órdenes normativos (la Ley Orgánica Constitucional de Bases Generales de la Administración del Estado, la Ley Orgánica Constitucional de Municipalidades, o incluso el Código Civil). De hecho, aún subsisten líneas jurisprudenciales que aplican reglas textuales distintas; ahora bien, en cuanto al fondo, las soluciones de la jurisprudencia no difieren sustancialmente. Por eso, la evolución del derecho debería conducir sin problemas, en el mediano plazo, a extender a todas esas instituciones el mismo régimen centrado en la falta de servicio.
} 
hechos ocurridos en el Hospital Naval de Valparaíso postula que tratándose de "una institución pública que forma parte de la Administración del Estado (...) resulta aplicable en el presente caso el régimen regulado en la Ley $\mathrm{N}^{\circ} 19.966 "{ }^{20}$ Este criterio debería recibir aplicación extensiva en casos similares.

Como se advierte, la ley ha recogido un enfoque funcional -definido por la materia sanitaria- y no puramente orgánico para determinar el ámbito de aplicación del régimen de responsabilidad. De aquí que en el desempeño puramente administrativo de los hospitales públicos, al margen de lo que sea que suponga la materia sanitaria, deban responder conforme al estatuto general de responsabilidad por falta de servicio. ${ }^{21}$

\subsection{Descripción general del sistema}

Según la ley, para dar lugar a la responsabilidad se exige acreditar la concurrencia de una falta de servicio del establecimiento hospitalario. Por el momento basta con tener en mente que la noción de falta de servicio corresponde a un defecto de funcionamiento o de organización del servicio público, idea que es muy próxima a la noción de culpa que emplea el derecho civil. De esa manera, el establecimiento de la responsabilidad hospitalaria supone un despliegue argumentativo (y probatorio) de imputaciones de culpa contra el hospital o sus agentes. En términos prácticos, el sistema opera de modo similar a la responsabilidad civil por culpa de hospitales y clínicas privadas.

El modelo reproduce el régimen general de responsabilidad por falta de servicio, conforme al cual el patrimonio estatal asume tanto las culpas atribuibles genéricamente al hospital (en cuanto servicio público) como varias de las faltas personales, esto es, culpas individuales de los funcionarios o agentes que laboran en el establecimiento. En buen grado, las nociones de falta de servicio y falta personal suponen, respectivamente, la aplicación de regímenes de responsabilidad por hecho propio y de responsabilidad por hecho ajeno. Teóricamente, la acción de repetición del Estado contra su agente incurso en falta personal es posible, aunque poco frecuente

\footnotetext{
${ }^{20}$ Corte Suprema, 14 de noviembre de 2017, Rol No 83.397-2016.

${ }^{21}$ Para un ejemplo de responsabilidad por falta de servicio derivada del incumplimiento de las condiciones laborales, que determina la enfermedad profesional de un funcionario del hospital, v. Corte Suprema, 14 de agosto de 2017, Rol № 95.182-2016.
} 
en la práctica. El Estado asume por lo común las consecuencias del mal funcionamiento del servicio considerado como un complejo organizacional.

Además, un entendimiento usual sobre la falta de servicio ve en ella una culpa difusa, colectiva o anónima del servicio público. ${ }^{22}$ Este factor explica la dilución de las responsabilidades individuales en general en el derecho administrativo. En materia hospitalaria, muchos fallos se conforman con sindicar al "equipo médico" como el origen de la falta de servicio. ${ }^{23}$ Así, los incentivos están puestos para que los litigantes apunten globalmente a los comportamientos del servicio hospitalario, sin detenerse en la identidad precisa del funcionario autor del daño, ni sus tareas o calificaciones profesionales.

\subsection{La noción de falta de servicio}

Sin duda, la noción central del régimen es la de falta de servicio. Esta es una traducción prácticamente literal de la noción francesa de faute de service y, al igual que su antecedente francés, corresponde, en general, a una culpa institucional de los organismos públicos. ${ }^{24} \mathrm{El} \mathrm{derecho} \mathrm{positivo} \mathrm{chileno}$ no cuenta con una definición normativa de la falta de servicio. Por eso, en su determinación en concreto la jurisprudencia suele recurrir a los desarrollos doctrinales tendientes a conceptualizarla.

De nuevo, son nociones de origen francés las que mayor repercusión han tenido. Por una parte, la descripción clasificatoria de Paul Duez entiende concurrir la falta de servicio cuando el servicio u organismo público no actúa debiendo hacerlo, actúa mal o tardíamente. ${ }^{25}$ Por otra, la noción más moderna de André de Laubadère, que la jurisprudencia chilena ha tendido a hacer suya,

\footnotetext{
${ }^{22}$ Las instituciones administrativas son organismos complejos, compuestos por varios agentes, medios materiales apropiados y una administración que gestiona esos distintos recursos y sus necesidades. Por eso, desde su teorización temprana por la doctrina francesa, la falta de servicio ha presentado un cierto carácter colectivo o anónimo en que la individualidad de los agentes públicos se funde en la gestión pública. V. Duez, Paul. La responsabilité de la puissance publique (en dehors du contrat), Dalloz, París, 1938, $2^{\text {a }}$ ed., pp. 21 y ss.

${ }^{23}$ También es así en el terreno hospitalario. La jurisprudencia abunda en referencias a faltas de servicio cometidas por el "equipo médico", sin especificar sus integrantes ni la intervención que hubieren tenido. Por lo demás, aun sin radicar la culpa en entelequias colectivas, bajo la idea de una mala atención brindada al paciente muchas veces se esconden comportamientos atribuibles a distintas categorías de profesionales o simples agentes administrativos.
}

${ }^{24}$ BARros, cit. (n. 3), pp. 485 y ss.

${ }^{25}$ Duez, cit. (n. 20), p. 27. 
atiende al establecimiento de la "mala organización o el funcionamiento defectuoso del servicio, apreciando esas nociones en forma objetiva, por referencia a lo que se está en derecho de exigir de un servicio público moderno, es decir, a aquello que debe ser su comportamiento normal". ${ }^{26}$

Conforme al régimen general, el ámbito de aplicación de la falta de servicio se extiende, salvo excepción, a toda la administración del Estado. Por eso, su definición tiene una plasticidad que la hace susceptible de aplicarse a todo tipo de servicios públicos, de funciones administrativas y de situaciones. Así como la culpa se entiende usualmente como incumplimiento de una obligación preexistente, la falta de servicio se proyecta como incumplimiento de un patrón de conducta esperable del servicio público.

La concretización de la falta de servicio depende de los deberes de servicio o estándares de actuación exigibles de cada tipo de institución pública. En el terreno de la medicina pública, la falta de servicio depende fundamentalmente de la conjugación de dos factores: la índole técnica de las prestaciones sanitarias y la categorización de prestaciones correspondientes a distintos tipos de instituciones. Por una parte, lo genuinamente específico de la responsabilidad hospitalaria reside en las prestaciones sanitarias que proveen estas instituciones. Luego, resulta crucial definir los deberes del establecimiento sanitario para con sus usuarios, ${ }^{27}$ ya sea que estos deberes conciernan al aparato administrativo o se refieran al desempeño de su personal, incluidos los médicos u otros profesionales de la salud. ${ }^{28}$ Por otra parte, la categorización de los establecimientos tiene evidente incidencia en el tipo de prestaciones que ahí se otorgan y a las que los usuarios pueden legítimamente aspirar. Desde la perspectiva de los niveles de servicio, sin duda un consultorio municipal no guarda comparación con un hospital. Aun dentro de los establecimientos hospitalarios cabe distinguir tres categorías

\footnotetext{
${ }^{26}$ Laubadère, André de; Venezia, Jean-Claude; Gaudemet, Yves, Traité de droit administratif, LGDJ, París, 1999, $15^{\text {a }}$ ed., T. I, p. 983. Esta misma fórmula pero ha sido adaptada por algunas sentencias chilenas, como: Corte de Apelaciones de Rancagua, 31 de diciembre de 2010, Rol Nº471-2010, cons. $4^{\circ}$, con cita a Pedro Pierry, cfr. Corte Suprema, 13 de abril de 2011, Rol No 1.093-2011; y Corte Suprema, 23 de diciembre de 2011, Rol N 6599-2009.

${ }^{27}$ Sin desmerecer que también hay falta de servicio en la infracción de deberes del hospital para con terceros o sus funcionarios; cfr. n. 20.

${ }^{28}$ Esto no significa que la falta de servicio sea el reflejo de la culpa del funcionario autor del daño. En tal sentido, en Salgado Castro la Corte Suprema ha rechazado que la falta de servicio solo concurra en caso de culpa grave (imprudencia temeraria o dolo) de los médicos, agregando "que en la responsabilidad por falta de servicio no es necesario identificar al funcionario causante del hecho, ni menos probar su culpa o dolo": Corte Suprema, 7 de abril de 2014, Rol N 13.418-2013, cons. $5^{\circ}$.
} 
distintas, definidas reglamentariamente. ${ }^{29} \mathrm{La}$ idoneidad funcional de cada establecimiento es específica: en principio, no todos están capacitados para enfrentar idénticas dolencias o circunstancias y, por lo mismo, no todos cuentan con idénticos medios instrumentales. De esta consideración más o menos general debieran seguirse consecuencias en este campo, pero también en el del desempeño del personal. Por último, cabe tener en cuenta una orientación jurisprudencial cada vez más fuerte a inferir la falta de servicio (o tal vez los deberes de servicio) a partir de la frustración de los derechos de los usuarios. Esta técnica genera alguna inquietud tratándose de derechos de contenido poco denso, como los derechos fundamentales, pero podría tener una aplicación más ortodoxa en presencia de derechos mejor delineados, como ocurre con los derechos del paciente, actualmente positivados por la ley. ${ }^{30}$

\section{LA RESPONSABILIDAD POR FALTA DE SERVICIO Y LAS RESPONSABILIDADES OBJETIVAS}

Por su pertenencia a la familia de las responsabilidades por culpa, el sistema de la falta de servicio se sitúa en las antípodas de la responsabilidad objetiva. Mientras en la responsabilidad objetiva (o sin culpa) basta con la ocurrencia de un daño causalmente provocado por un hecho ocurrido dentro del ámbito de riesgos del responsable, independientemente de que ese hecho sea grosso modo reprochable, en la responsabilidad por falta de servicio se requiere demostrar un defecto, irregularidad o anomalía en el hecho que provoca el daño.

Esta precisión sería innecesaria si en un pasado no tan distante no se hubieran confundido estas dos categorías dogmáticas por parte de la jurisprudencia y de la literatura especializada. ${ }^{31}$ Ocasionalmente todavía

\footnotetext{
${ }^{29}$ Siguiendo orientaciones trazadas por la Ley $\mathrm{N}^{\circ} 19.937,2004$, establece que todos los hospitales públicos "se clasificarán en establecimientos de alta, mediana o baja complejidad, de acuerdo a su capacidad resolutiva", atendiendo a criterios como su función al interior de la red, los "servicios de apoyo diagnóstico y terapéutico (con que cuentan,) considerando su resolutividad, disponibilidad de recurso humano, equipamiento, horario de atención y procedimientos o exámenes que realiza" y la "especialización de sus recursos humanos" (artículo 44). La clasificación respectiva se efectúa caso a caso por el Ministerio de Salud a proposición del respectivo servicio de salud (artículo 45).

${ }^{30}$ Ley $\mathrm{N}^{\circ} 20.584,2012$.

${ }^{31}$ Cfr., por todos, VÁsQuez Rogat, Andrés, Responsabilidad del Estado por sus servicios de salud, Ed. Conosur, Santiago 1999.
} 
se registran pronunciamientos sorprendentes en este plano, ${ }^{32}$ pero hoy es inequívoco que la responsabilidad se configura a partir de una falta de servicio. $^{33}$

Viendo al fondo de las cosas, el modelo de la responsabilidad objetiva en materia sanitaria pública plantea preguntas políticas muy sensibles, porque podría implicar que el Estado tuviera que hacerse cargo de todas las consecuencias del estado de salud del paciente, desde que éste se pone bajo el cuidado del servicio público. Se trataría de un sofisticado modelo de asistencia o seguridad social, que tendría graves consecuencias sobre las finanzas públicas. Es difícil aceptar estos mecanismos de responsabilidad sin una base normativa asumida en términos conscientes y explícitos por la comunidad política.

La pertenencia ideológica de la responsabilidad por falta de servicio a la familia de regímenes de responsabilidad por culpa se muestra en dos rasgos particulares, que conciernen al tipo de deberes de servicio en este campo y a la prueba de la responsabilidad.

\subsection{Estructura de los deberes de servicio en materia hospitalaria}

Un acercamiento tradicional a la responsabilidad en el ámbito médico desde el derecho de contratos ha tendido a excluir el modelo de responsabilidad basado en la violación de una obligación de resultados, prefiriendo el modelo de la obligación de medios. ${ }^{34}$ Esta orientación tiene sentido, desde que la condición habitual del paciente que ingresa al hospital hace probable la ocurrencia de un daño fisiológico. La obligación del hospital no puede, a priori, consistir en curar al paciente, sino en tratar adecuadamente sus dolencias. Por cierto, la distinción entre obligaciones de medio y de resultados tiene su lugar dogmático en la responsabilidad contractual, cuyo patrón de referencia es la promesa que se han hecho las partes en el marco de su autonomía negocial, y no juega per se en la

\footnotetext{
${ }^{32}$ Por ejemplo, Corte de Apelaciones de Talca, 4 de noviembre de 2016, Rol № 1.223-2016: la expresión falta de servicio "ha sido entendida como una responsabilidad objetiva, pero que en otros casos se ha conceptualizado como subjetiva. Empero, en los casos en que se ha entendido como objetiva, es fácil advertir la existencia de una negligencia médica" (cons. 7).

${ }^{33}$ Así, CÁRDENAS y MoReno, cit. (n. 4), p. 63: "no es posible hallar una sola sentencia que haya aplicado una responsabilidad de este tipo" (es decir, objetiva o estricta). Cfr. Corte Suprema, 22 de julio de 2019, Rol N 12.486-2019, atribuyendo "la calidad de subjetiva" a la "responsabilidad sanitaria".

${ }^{34}$ V. BARros, cit. (n. 3), p. 679, con referencia al carácter excepcional de las obligaciones de resultado en el terreno médico en el derecho civil.
} 
responsabilidad extracontractual.

Ahora bien, la jurisprudencia se ha referido expresamente a esta distinción en el campo de la responsabilidad sanitaria del Estado. Por ejemplo, recientemente en Quilodrán Ramírez la Corte Suprema explícitamente razona que "la configuración de la responsabilidad administrativa debe (...) necesariamente vincularse a la naturaleza de la obligación médica que (...) se trata de una de medios, esto es, el profesional actuante debe ajustar su conducta a la lex artis médica, no debe necesariamente curar o sanar al paciente, sino desplegar su actividad cumpliendo estándares de conocimiento, prudencia y diligencia". ${ }^{35}$ Este modo de razonar sugiere que para la jurisprudencia los estándares de servicio relevantes se entienden preferentemente configurados al modo de los deberes de prudencia, de modo que la falta no se infiere simplemente a partir del resultado dañoso consistente en no sanar al enfermo. Al contrario, se necesita demostrar fehacientemente que el deber de diligencia no ha sido cumplido. Por cierto, esta orientación general de la responsabilidad médica no obsta a la proliferación de un número variable de deberes de servicio configurados como deberes determinados (o, si se quiere, de resultado) y cuya transgresión es más sencilla de demostrar.

\subsection{El sistema de la culpa probada}

El modelo legal se ve reforzado por el sistema de la culpa probada. El antes transcrito artículo 38 de la Ley 19.966 dispone al efecto que el demandante "deberá acreditar que el daño se produjo por la acción u omisión del órgano, mediando dicha falta de servicio". En lo inmediato, la regla impone la carga de la prueba al paciente, que es la víctima del daño. Pero yendo al fondo, la consecuencia de este diseño consiste en que el paciente no obtendrá indemnización a partir de las simples consecuencias de su afección inicial o de su evolución normal o previsible, a menos de demostrar que el daño haya sobrevenido o se haya agravado por una causa distinta, imputable al servicio y susceptible de calificarse como falta de servicio. ${ }^{36}$

Ahora bien, esta definición del onus probandi no es incompatible

\footnotetext{
${ }^{35}$ Corte Suprema, 13 de noviembre de 2017, Rol № 99.898-2016 (cons. $5^{\circ}$ ). El argumento aquí sirve de base para configurar una noción de culpa como violación a la lex artis, aunque sin mayores consecuencias concretas. El mismo razonamiento se repite, literalmente, en Corte Suprema, 27 de febrero de 2018, Rol N²1.599-2017.

${ }^{36}$ He sostenido esta opinión en VALDIVIA Olivares, José Miguel, "La culpa médica en la responsabilidad de los hospitales públicos", Revista Médica de Chile, 2018, Vol. 146, p. 1028 y ss.
} 
con el "principio de adquisición" de la prueba, de modo que incluso los antecedentes aportados por el demandado pueden servir para dar por establecida la falta de servicio. Más aun, el régimen de culpa probada convive con presunciones de culpa construidas ocasionalmente por los jueces a partir de los datos aportados por las partes. ${ }^{37}$

\subsection{La responsabilidad individual del personal del hospital}

En el sistema de la falta de servicio es frecuente que las culpas individuales de los agentes del servicio público sean cubiertas por el patrimonio estatal. En sí misma, la falta de servicio es una expresión alegórica, porque el servicio sólo actúa por medio de personas humanas; en la falta de servicio yace, pues, una técnica de imputación de los actos de los agentes públicos al servicio público por cuya cuenta actúan. ${ }^{38}$ En otras palabras, este mecanismo de responsabilidad implica que algunas culpas humanas se califican como faltas de servicio y, por tanto, se imputan directamente al servicio público (sin que puedan considerarse culpas propias de sus autores inmediatos). ${ }^{39}$ Pero, además, el sistema propende -desde temprano en la tradición francesa- a la cobertura estatal, al menos provisoria, de algunas faltas personales o culpas propias de sus autores, aunque no se imputen al servicio público. ${ }^{40}$ La jurisprudencia chilena ha llegado al extremo de

${ }^{37}$ En Corte Suprema, 31 de julio de 2012, Rol No 9.140-2009, a partir de la presencia de compresas en el paciente, detectadas a raíz de una infección consecutiva a una operación, la Corte Suprema infiere una falta de servicio consistente en haberlas dejado por descuido. La Corte dice fundarse en el artículo 1698 del Código Civil -regla fundamental del onus probandi-, pero esa referencia apenas logra ocultar el origen jurisprudencial de esta presunción (de culpa y de causalidad), que era extremadamente difícil de justificar en derecho positivo.

${ }^{38}$ Entre otros, v. Valdivia Olivares, José Miguel, "Teoría del órgano y responsabilidad pública en la Ley de Bases de la Administración del Estado", Revista de Derecho (Valdivia), 2006, Vol. 19.

${ }^{39}$ En Salgado Castro la Corte de Apelaciones de La Serena estimó que "para que exista responsabilidad de los órganos del Estado por falta de servicio de sus agentes es necesario acreditar la imprudencia temeraria o el dolo de éstos"; en otras palabras, desconoció la diferencia entre falta de servicio y falta personal. La Corte Suprema casa el fallo por error de derecho: Corte Suprema, 7 de abril de 2014, Rol $\mathrm{N}^{\circ} 13.418-2013$.

${ }^{40}$ La justificación de esta cobertura, aunque debatida, parece ser pragmática. En casos de cúmulo de faltas o de responsabilidades es difícil separar la parte que debiese gravar al funcionario o al Estado. Para los casos de falta personal no desprovista de todo vínculo con el servicio la justificación es más compleja, porque (por definición) no hay falta de servicio, pero se produciría una incoherencia axiológica de aceptar que estos casos quedasen sin compensación estatal, en circunstancias que esa falta personal parece menos grave que las de los casos de cúmulo, que sí quedan cubiertas. El germen de esta idea, en JEZE, Gaston, "De la responsabilité pécuniaire des patrimoines administratifs au cas de faute personnelle", Revue du Droit Public, 1914, pp. 569 y ss. 
reconocer que incluso una falta personal no desprovista de todo vínculo con el servicio justifica la responsabilidad estatal, ${ }^{41}$ sin perjuicio de su repetición posterior contra el agente.

La distinción entre falta de servicio y falta personal no obedece a criterios conceptuales muy bien definidos. En la falta de servicio se aprecia más bien al agente público, mientras que en la falta personal, más bien al hombre desprovisto de calificaciones. ${ }^{42}$ Pero los antecedentes franceses de estas nociones sugieren que los deslindes entre ambas categorías fluctúan en función del peso de consideraciones pragmáticas, de modo que la falta personal se entienda "aquella que, en el marco de una buena política jurisprudencial, conviene dejar a cargo de su autor, y (correlativamente) la falta de servicio aquella que sería inoportuno o injusto hacerle soportar personalmente". ${ }^{43}$

Así las cosas, no es extraño que, como ocurre en Llanca Viguera, el Estado deba responder en nombre del Hospital Naval por la falta personal de una matrona que, al asear a una paciente, vierte agua caliente sobre sus tejidos, provocándole graves quemaduras. ${ }^{44}$

A pesar de que la cobertura por el Estado de las culpas de sus agentes diluye el sentido de las responsabilidades individuales, el establecimiento de la falta personal no es trivial. Las virtudes pedagógicas u orientativas de un sistema basado en la culpa se despliegan adecuadamente en cuanto puedan identificarse aquellas conductas que no debieran volver a repetirse.

El dispositivo especial de la Ley 19.966 no utiliza la expresión falta personal sino que, a diferencia de otros textos legales que consagran el

\footnotetext{
${ }^{41}$ Corte Suprema, 14 de enero de 2011, Rol N 7.919-2008. Esta sentencia reproduce la solución francesa a que se había llegado por el Conseil d'Etat, 18 de noviembre de 1949, Recueil Lebon, 1949, p. 492 y ss.

${ }^{42}$ A la hora de deslindar estas dos especies de culpa, la literatura suele retornar a la fórmula de Edouard Laferrière en sus conclusiones para el fallo Laumonier-Carriol (Tribunal des Conflits, 5 de mayo de 1877, Recueil Lebon, 1877, p. 437 y ss.): "si el acto dañoso es impersonal o si revela a un administrador o un mandatario del Estado más o menos sujeto a error, y no al hombre con sus debilidades, sus pasiones o imprudencias, el acto es administrativo" y, en cambio, si "la personalidad del agente se revela por faltas de derecho común, vías de hecho o imprudencia, entonces la culpa es imputable al funcionario, no a la función".

${ }^{43}$ LoNG, Marceau, "La responsabilité de l'administration pour les fautes personnelles commises par ses agents à l'occasion du service", Etudes et Documents du Conseil d'Etat, 1953, p. 80.

${ }^{44}$ Corte Suprema, 4 de septiembre de 2012, Rol N 8.044-2010. A pesar de la declaración en tal sentido de la Corte, es discutible que se trate propiamente de una falta personal; más aún, otros antecedentes del caso revelan que se trata de una falta de servicio, en cuanto se trataba de un acto propio de la función. Es posible que en la calificación de falta personal hayan pesado antecedentes de orden disciplinario respecto de la matrona.
} 
mismo régimen, recurre a las ideas de "imprudencia temeraria o dolo" ${ }^{45} \mathrm{La}$ interpretación más razonable de esta regla consiste en que la falta personal en el campo de la responsabilidad sanitaria es una culpa grave. ${ }^{46} \mathrm{Sin}$ duda, las nociones empleadas por la ley tienen una connotación penal fuerte, ${ }^{47}$ pero, más allá de la literalidad de las palabras, su entendimiento como casos de culpa grave es consistente con las orientaciones generales de la jurisprudencia chilena $^{48}$ y del derecho comparado. ${ }^{49}$ Por cierto, al igual que ocurre con la falta personal en otros campos, es poco usual que los organismos públicos persigan la responsabilidad individual de sus agentes en el terreno médico. ${ }^{50}$

\section{IV. ÁMBITOS DE LA RESPONSABILIDAD SANITARIA}

\subsection{La distinción}

La determinación concreta de la falta de servicio depende de los deberes contextuales del establecimiento sanitario en las circunstancias del daño. En otros términos, para estimar que el hospital ha incurrido en falta de servicio es necesario atender al tipo de situación en que acaece el daño. Así, cuando el daño ocurre en razón del desempeño del médico, la falta de servicio reviste aspectos singulares, porque el juicio de responsabilidad exige prestar atención a los deberes propios del profesional, que la jurisprudencia (y la literatura en general) identifican con la expresión lex artis. En contraste, la determinación de la falta de servicio es relativamente sencilla cuando no

${ }^{45}$ Ley 19.966, 2004, artículo 38, inciso 3.

${ }^{46}$ Así, Corte Suprema, 14 de agosto de 2017, Rol No 76.284-2016.

${ }^{47}$ La tipificación básica de los cuasidelitos contra las personas, en el Código Penal chileno, se efectúa de este modo: "El que por imprudencia temeraria ejecutare un hecho que, si mediara malicia, constituiría un crimen o un simple delito contra las personas, será penado..." (artículo 490).

${ }^{48}$ Entre otras, v. en este sentido, Corte Suprema, 30 de enero de 2014, Rol No 9.006-2013.

${ }^{49}$ Por ejemplo, en el derecho español, el artículo 36.2 de la Ley 40-2015, de Régimen Jurídico del Sector Público dispone: "La Administración correspondiente, cuando hubiere indemnizado a los lesionados, exigirá de oficio en vía administrativa de sus autoridades y demás personal a su servicio la responsabilidad en que hubieran incurrido por dolo, o culpa o negligencia graves, previa instrucción del correspondiente procedimiento".

${ }^{50}$ Es difícil sacar lecciones del caso Elgueta Parodi, por incidir en un caso anterior a la vigencia de la Ley $\mathrm{N}^{\circ} 19.966$, de 2004 y saldarse parcialmente mediante una transacción: Corte Suprema, 12 de junio de 2007, Rol N ${ }^{\circ}$ 2.954-2006. Tampoco es muy ilustrativa la situación de que da cuenta Corte Suprema, 21 de julio de 2009, Rol № 2.849-2009, en que se impugna el cobro administrativo de una condena establecida-verosímilmente- también antes de la Ley $\mathrm{N}^{\circ} 19.966$. 
está en juego la intervención del médico, sino de otros agentes del hospital o establecimiento.

Estos son los dos grandes ámbitos de la responsabilidad en materia sanitaria: el de la responsabilidad médica, es decir, de aquella que surge por la participación del médico en la ejecución de prestaciones médicas, y el de los demás casos, en que intervienen otros profesionales o personas, o simplemente el daño proviene del funcionamiento del establecimiento hospitalario.

Esta distinción aparece recogida, de manera algo gruesa, por el fallo Morales Quezada con Servicio de Salud del Bio-Bio. En el caso se discutía acerca de la responsabilidad de un servicio de salud a raíz de la caída de un paciente desde una camilla durante su traslado; la defensa del servicio pretendió excusarse en que en el hecho no se había transgredido la lex artis pero, por impertinente, esta excusa fue rechazada por la Corte Suprema. En materia sanitaria hay que distinguir el terreno de "la prestación médica que recibe un paciente conforme a su estado de salud, en la cual cobra relevancia el cumplimiento de la lex artis, del resto de las atenciones o servicios que un paciente recibe o espera recibir cuando acude a un centro asistencial. En efecto, lo que (se) reprocha al órgano demandado no está relacionado con la prestación médica propiamente tal sino con el servicio de traslado del paciente hacia el centro de urgencia que obviamente no se rige por la lex artis". ${ }^{51}$

\subsection{Sentido de la distinción}

En Morales Quezada la distinción aparece oscurecida por una apresurada opinión de la Corte sobre el método de determinación de la falta de servicio. En efecto, la Corte postula que la lex artis no es un criterio referencial que permita determinar los deberes de servicio durante el traslado de un paciente, materia que se rige "por protocolos de procedimientos que la propia institución ha instaurado con ese fin". ${ }^{52}$ Un rápido vistazo a la jurisprudencia muestra que este razonamiento incurre en un error, porque

\footnotetext{
${ }^{51}$ Corte Suprema, 6 de noviembre de 2012, Rol No 5.417-2012. Las circunstancias del caso facilitaban esta distinción: la víctima directa, paciente "posiblemente terminal", de 97 años de edad, cayó de una camilla mientras era trasladado al hospital, lo que agravó su estado de salud. La defensa fiscal pretendía que la víctima había recibido la atención médica correcta, sin que se hubiera infringido la lex artis, razonamiento impertinente atendidos los hechos reseñados.

${ }^{52}$ Ibidem.
} 
para inferir los deberes de los médicos, en miras de dar por establecida la falta de servicio, los jueces también recurren al análisis de protocolos. ${ }^{53} \mathrm{Un}$ fallo ha llegado al extremo de referirse a este tipo de especificaciones, que son una especie de codificación informal de las técnicas de la profesión, como "protocolo configurativo de la lex artis". ${ }^{4}$ Sin duda el examen de estos textos es una técnica que facilita el reconocimiento de la falta de servicio, porque agiliza la identificación de los deberes técnicos de los profesionales $\mathrm{y}$, como si se tratara de genuinas reglas, también simplifica el reconocimiento de la culpa a partir de la simple transgresión de tales deberes. ${ }^{55}$ Por cierto, la persistente reconducción a la lex artis como criterio rector en este plano deja en evidencia que el examen de los protocolos no podría agotar el análisis de la culpa médica.

Sin embargo, aun errónea, esa apreciación de Morales Quezada tiene valor, porque revela que para la Corte Suprema el juicio de responsabilidad es más exigente y menos mecánico cuando se trata de analizar el desempeño del médico, en comparación con asuntos en que sólo está en juego la participación de personal menos calificado. El tratamiento singular del acto médico desde la perspectiva de la responsabilidad está tradicionalmente arraigado en el derecho civil y aun en el derecho penal; es razonable que también sea así en el derecho administrativo. La distinción da cuenta de la pervivencia de la alta consideración que históricamente se ha tenido por la medicina, cuyos conocimientos profesionales se adquieren al cabo de estudios universitarios de los más prolongados que hay y que, en la percepción común, todavía parece situarse en el umbral que separa la vida de la muerte.

Además, la medicina se ejerce en condiciones especialmente delicadas. Una intervención quirúrgica, aunque haya sido programada, despierta situaciones imprevistas que hay que resolver en el minuto, con sentido de oportunidad. Desde luego, el médico no tiene un control absoluto sobre

\footnotetext{
${ }^{53}$ Algunos ejemplos de su relevancia en el establecimiento de la responsabilidad: Corte Suprema, 23 de marzo de 2016, Rol N²1.019-2015 (respecto de la "Guía clínica para la prevención del parto prematuro") y Corte Suprema, 8 de agosto de 2017, Rol N 97.628-2016 (respecto de la "Guía clínica para el manejo de mordedura de araña de rincón", calificado por el fallo como "protocolo configurativo de la lex artis"). V. también, para una solución más matizada, Corte Suprema, 25 de abril de 2017, Rol N ${ }^{\circ}$ 34.836-2016 (traslado de un paciente potencialmente incompatible con la Guía clínica sobre infección respiratoria baja de manejo ambulatorio en menores de 5 años). Con referencia a las "Orientaciones técnicas para la atención integral de mujeres que presentan un aborto y otras pérdidas reproductivas", Corte Suprema, 24 de enero de 2017, Rol N 78.933-2016.

${ }^{54}$ Corte Suprema, 8 de agosto de 2017, Rol N 97.628-2016.

${ }^{55}$ Lo he sostenido previamente en VALdivia, cit. (n. 36).
} 
el paciente, aunque esté informado de su historial y principales dolencias. Incluso si el paciente entrega al médico información adecuada (lo que no siempre es posible, porque el paciente suele no entender lo que le ocurre), sus síntomas pueden ocultar otros males; además, la fisiología de cada paciente es única, lo que explica que no todos reaccionen de igual manera a un mismo tratamiento.

Por eso se entiende que a pesar del florecimiento de algunas técnicas que facilitan el reconocimiento de la culpa médica en el derecho público, la distinción entre actos médicos y no médicos aparezca, metodológicamente, como la primera operación intelectual del juez en este campo y subsista como summa divisio en el análisis de la materia.

\subsection{Efectos de la distinción}

La distinción entre el ámbito médico y el no médico no se traduce en la existencia de regímenes distintos de responsabilidad, pues en ambos casos rige la responsabilidad por falta de servicio. En el derecho chileno no ha prosperado la pretensión de establecer una gradación de culpas en esta materia, que supondría el reconocimiento de una responsabilidad por culpa grave tratándose de actos médicos, ${ }^{56}$ como alguna vez fue el caso del derecho francés. ${ }^{57}$ Ahora bien, sin perjuicio del carácter unitario del régimen de responsabilidad, la plasticidad de la idea misma de falta de servicio explica que en uno de estos terrenos la responsabilidad se vea comprometida de modo más sencillo que en el otro, en que se requiere de un juicio más sofisticado, con apoyo en consideraciones técnicas.

La configuración del hospital como establecimiento complejo, en que el personal médico sólo es uno de los múltiples factores que participan en las prestaciones sanitarias, facilita que a la hora de imputar responsabilidades las víctimas acusen indistintamente faltas de servicio médicas y otras que no lo son. En la medida que la falta de servicio no médica es a priori más fácil de configurar, esta estrategia debería conducir a un reconocimiento más sencillo de la responsabilidad. Sin embargo, la diferencia entre faltas

\footnotetext{
${ }^{56}$ Fue sugerida por Pierry Arrau, Pedro. "La falta de servicio en la actividad médica", Revista de Derecho del Consejo de Defensa del Estado, 2003, N 8, p. 149 y ss.

${ }^{57}$ Esta orientación parece comenzar en Conseil d'Etat, 26 de junio de 1959, Recueil Lebon, 1959, p. 405. Sin embargo, el abandono de esta jurisprudencia fue oficializado por Conseil d'Etat, 10 de abril de 1992, incluido en Long, Marceau; Weil, Prosper; Braibant, Guy; Delvolvé, Pierre; Genevois, Bruno, Les grands arrêts de la jurisprudence administrative, Dalloz, París, 1999 12a ed., p. 761 y ss.
} 
de servicio médicas y no médicas no ha perdido su sentido. En cuanto la falta de servicio descansa en la infracción de deberes de servicio, la adecuada identificación de las faltas de servicio es de enorme importancia en la determinación de los deberes de cada uno dentro del establecimiento hospitalario. La finalidad de orientación de conductas a que propende todo régimen de responsabilidad por culpa se cumple mejor cuando el juicio de responsabilidad identifica adecuadamente las faltas personales o de servicio en que cada uno pudo incurrir.

Con estas prevenciones en mente, corresponde analizar estos dos ámbitos específicos de la responsabilidad hospitalaria.

\section{a) La falta de servicio en el campo médico}

En el universo de casos de responsabilidad médica, los ejemplos más representativos de falta de servicio son los errores de diagnóstico y de materialización de un tratamiento (incluidas las intervenciones quirúrgicas). Entre el diagnóstico de una dolencia y la ejecución material del tratamiento que corresponde, el médico prescribe el modo de enfrentar el estado del paciente, por ejemplo, mediante medicación o algún procedimiento; teóricamente, en este campo también hay espacio para la comisión de faltas de servicio, aunque en la experiencia jurisprudencial éstas se muestren muy escasas. ${ }^{58}$

a.1.- Defectos de diagnóstico.

El diagnóstico del estado de salud es la primera actuación médica que recae sobre el paciente, tendiente precisamente a averiguar su condición, en miras a establecer un curso de acción a seguir. Sea que se efectúe por la simple auscultación o apreciación del médico o mediante la práctica de exámenes técnicos (que es necesario interpretar), el diagnóstico no suele provocar directamente daños al paciente, ${ }^{59}$ pero puede estar mediatamente

\footnotetext{
${ }^{58}$ Hay excepciones, como parece ser el caso de Corte Suprema, 21 de febrero de 2018, Rol № 18.172 2017: hernia de disco dorsal tratada mediante cirugía en vez de medios menos invasivos preconizados por el protocolo respectivo. Otros casos similares, pero con componentes más complejos: Corte Suprema, 6 de julio de 2018, Rol $\mathrm{N}^{\circ}$ 38.838-2017: prescripción de medicamento convulsivo, inapropiado para paciente epiléptico -aunque el daño posiblemente se deba a una insuficiente valoración de la epilepsia-; y Corte Suprema, 18 de junio de 2018, Rol No 6.549-2018: prolongación del trabajo de parto normal y cesárea tardía, posiblemente imputable a una insuficiente valoración del estado físico de la parturienta.

${ }^{99}$ V. sin embargo, Corte Suprema, 17 de junio de 2019, Rol N 2.468-2018: lesión causada durante la práctica de una colonoscopía. Un caso más singular en Corte Suprema, 4 de julio de 2017, Rol N ${ }^{\circ}$
} 
en su origen cuando, en razón del error, no se consiga determinar la dolencia del paciente y profundice sus efectos, o derive en un tratamiento inapropiado que genere consecuencias nocivas.

¿Cuándo un error de diagnóstico es constitutivo de una falta de servicio? Asumiendo que siempre es posible determinar ex post la condición del paciente, el mero desajuste objetivo entre su estado de salud y las predicciones del médico no basta para configurar un error de diagnóstico constitutivo de falta de servicio. La relevancia de la (infracción a la) lex artis en la identificación de la culpa médica exige demostrar un comportamiento positivo del médico en la práctica del diagnóstico para que el Estado se entienda responsable.

El análisis de la jurisprudencia permite apreciar la existencia de dos grandes categorías de errores de diagnóstico constitutivos de falta de servicio. Por una parte, el error de diagnóstico es culpable si ha sido irregular en razón de la omisión de las averiguaciones o exámenes pertinentes. Este parece ser el caso de Burgos Fabres, en que el hospital omite practicar pruebas de laboratorio para indagar la existencia de un rotavirus que cobra la vida de un menor. ${ }^{60}$ Ahora bien, la forma privilegiada de error de diagnóstico consiste en un error de juicio provocado por apartarse de los antecedentes técnicos disponibles, tales como los exámenes relativos al paciente. Por ejemplo, en Salgado Durán la paciente es sometida a exámenes que sugieren una trombosis, aunque posteriormente éstos no son tomados en cuenta, tanto para disponer el alta como para su atención posterior. ${ }^{61}$ El caso más extremo de un error de diagnóstico de esta especie es Fernández Flores, en que el facultativo se equivoca en la comunicación de los resultados de un examen cuya interpretación no requiere de mayores ponderaciones. ${ }^{62}$

\footnotetext{
95.114-2016: con ocasión de una prueba tendiente a determinar la tolerancia a la glucosa, previa a una intervención quirúrgica, un paciente experimentó una reacción adversa que no pudo ser enfrentada en el centro de salud municipal, y que según la Corte corresponde a un shock anafiláctico. Con todo, la falta de servicio no se produce por la forma en que se condujo la prueba, sino al no haberse reconocido el cuadro de la paciente frente a la evidencia con que se presentaba.

${ }^{60}$ Corte Suprema, 5 de octubre de 2012, Rol № 5.604-2010. Últimamente, v. además, Corte Suprema, 1 de julio de 2019, Rol $N^{\circ} 7.755-2019$ (error de diagnóstico asociado a dificultad de practicar exámenes más idóneos) y Corte Suprema, 2 de julio de 2019, Rol N 4.272-2019 (omisión de evaluación preanestésica).

${ }^{61}$ Corte Suprema, 31 de julio de 2017, Rol No 8.355-2017. El caso se resuelve en aplicación del Código Civil, en razón de tratarse de un hospital perteneciente a una empresa del Estado; pero la técnica de establecimiento de la culpa es análoga a la que importaría el reconocimiento de una falta de servicio. ${ }^{62}$ Diagnóstico del VIH a un paciente que en realidad no lo había contraído, formulado sobre la base de un examen que sólo entrega resultados binarios: $3^{\circ}$ Juzgado de Viña del Mar, 17 de junio de 2010, confirmada por Corte Suprema, 6 de noviembre de 2012, Rol № 1.013-2011.
} 
Más allá de los casos de afecciones sencillas o evidentes ${ }^{63}$ es cuestionable establecer la falta de servicio por diagnóstico erróneo a partir de la simple circunstancia de que el médico no haya detectado la dolencia que aqueja al paciente. Así parece ocurrir, por ejemplo, en Pérez Aguilar, caso complejo en que un menor muere por causa de una afección que sencillamente no logra ser identificada. La Corte Suprema dirige un reproche severo contra el organismo demandado y su equipo de profesionales, que sólo conjeturaron una faringitis. "Como quedó en evidencia algunas horas después, dicha diagnosis era completamente errada y, por consiguiente, la medicamentación [sic.] y el tratamiento prescritos (...) no eran los adecuados, error que, como salta a la vista, permitió que su cuadro de base continuara evolucionando, hasta el punto (de) causarle la muerte". La Corte llama la atención sobre que el estado febril de la víctima "no había sido suficientemente aclarado ni menos aun controlado, desde que su origen era desconocido y, como es evidente, no obedecía a la presencia de un cuadro de faringitis". Es inequívoco que en el caso algo salió mal, pero no logra precisarse exactamente qué fue o de qué manera los médicos hubieran podido evitarlo. ${ }^{64}$ Este tipo de pronunciamientos ${ }^{65}$ defrauda el principio de la culpa probada, porque implica inferir la culpa del médico a partir de la patología o condición de salud del paciente, con prescindencia de sus esfuerzos, de los medios técnicos disponibles, de la complejidad del caso y de su urgencia. Por el contrario, la jurisprudencia descarta que haya falta de servicio cuando es el mismo estado de salud del paciente lo que dificulta efectuar diagnósticos certeros. ${ }^{66} \mathrm{Si}$ esta última orientación es correcta, el error de diagnóstico no se configura de modo objetivo (como un diagnóstico fallido) sino mediando una infracción a la lex artis.

Ahorabien, cabe advertir que con ocasión del acto médico de diagnóstico pueden cometerse otras faltas de servicio que no envuelven necesariamente errores de juicio, como ocurre en caso de tardanza de diagnóstico ${ }^{67} \mathrm{o}$ de

\footnotetext{
${ }^{63}$ Parece ser el caso de Corte Suprema, 4 de julio de 2017, Rol No 95.114-2016 (shock anafiláctico experimentado en el establecimiento sanitario).

${ }^{64}$ Corte Suprema, 26 de diciembre de 2017, Rol No 11.526-2017.

${ }^{65}$ Algo semejante ocurre en Pizarro Araya con Servicio de Salud de Coquimbo, en que la Corte Suprema declara la falta de servicio porque no consta "que durante las consultas médicas se le hubieran efectuado las pruebas y exámenes necesarios para descartar" un síndrome compartimental. Corte Suprema, 16 de mayo de 2016, Rol N 18.124-2015.

${ }^{66}$ Por ejemplo, Corte de Apelaciones de Valparaíso, 2 de septiembre de 1999, Rol N 2.934-1998 (apendicitis); Corte Suprema, 15 de noviembre de 2012, Rol N 2.411-2012 (carcinoma mamario).

${ }^{67}$ Corte Suprema, 9 de noviembre de 2017, Rol N ${ }^{\circ}$ 1.745-2017 (demora en detección de coqueluche, en circunstancias que un brote de la enfermedad se había anunciado oficialmente en la zona).
} 
desórdenes administrativos que tienen por efecto que el diagnóstico no se comunique al paciente ${ }^{68}$ o se produzcan demoras en el procedimiento. ${ }^{69}$ Sin embargo, es usual que estas faltas de servicio sean provocadas por la acción (exclusiva o concurrente) del personal administrativo del hospital, alejándolas del campo de la culpa médica propiamente tal.

\section{a.2.- Errores de tratamiento.}

Varios casos de culpas del médico que dan origen a la responsabilidad del Estado corresponden a defectos de materialización del tratamiento.

En un resonante caso de los años 1990 la responsabilidad del Estado por hechos ocurridos en el Hospital Militar fue reconocida porque, estando programada una operación de cadera derecha, el equipo médico intervino la izquierda. ${ }^{70}$ Por curioso que parezca, este tipo de inconsistencias en el tratamiento se ha reiterado, por ejemplo cuando un paciente es sometido a un procedimiento distinto del programado ${ }^{71} \mathrm{o}$, de modo mucho más insólito, cuando es operado sobre la base del diagnóstico correspondiente a otra persona. ${ }^{72}$ Estos casos se asemejan a otros en que el paciente no recibe el tratamiento prescrito, simplemente por olvido; por ejemplo, cuando una intervención que debía practicarse sencillamente no se lleva adelante. ${ }^{73} \mathrm{De}$ modo más trivial, el retraso en la práctica de una actuación médica también puede calificarse como falta de servicio, ${ }^{74}$ lo que es frecuente en la atención de partos. ${ }^{75}$ Debe advertirse, con todo, que la falta de servicio no siempre es imputable sólo al médico, sino a otros agentes del hospital. ${ }^{76}$

La culpa médica puede consistir, también, en un defecto de pericia del profesional. Por ejemplo, hay falta de servicio si con ocasión de una intervención quirúrgica se causan lesiones o heridas sin relación funcional con la intervención misma. ${ }^{77}$ Otras culpas relativamente frecuentes en el

\footnotetext{
${ }^{68}$ Corte Suprema, 19 de mayo de 2015, Rol ํ 4.388-2015.

${ }^{69}$ Corte Suprema, 14 de septiembre de 2016, Rol N 35.566-2015.

${ }^{70}$ Corte Suprema, 20 de junio de 1996, Rol N 33.393-1995 (“caso Béraud")

${ }^{71}$ Corte Suprema, 19 de mayo de 2016, Rol №32.268-2015 (vaciamiento axilar en vez de biopsia).

${ }^{72}$ Corte Suprema, 1 de junio de 2017, Rol No 87.914-2016.

${ }^{73}$ Corte Suprema, 29 de enero de 2016, Rol N 13.544-2015 (esterilización no practicada).

${ }^{74}$ Últimamente, Corte Suprema, 3 de septiembre de 2018, Rol N 40.328-2017.

${ }^{75}$ Por ejemplo, Corte Suprema, 2 de agosto de 2016, Rol N 16.002-2016.

${ }^{76}$ Por ejemplo, si no se cumple la orden de trasladar el paciente a una unidad especializada: Corte Suprema, 6 de junio de 2016, Rol N 1.574-2016.

${ }^{77}$ Corte Suprema, 28 de junio de 2016, Rol N 34.161-2015 y Corte Suprema, 22 de julio de 2019,
} 
quirófano se pueden establecer a partir del incumplimiento de deberes de orden práctico, como ocurre en el olvido de compresas o instrumental dentro del cuerpo del paciente. ${ }^{78}$

Atendida la creciente importancia de los derechos del paciente, la inobservancia de la exigencia de recabar el consentimiento informado del paciente frente a algún tratamiento también se entiende constitutiva de falta de servicio. ${ }^{79}$

\section{b) Las culpas del personal no médico}

Mientras la culpa médica tiene por protagonista a un profesional especialista, ocurre que en los establecimientos hospitalarios laboran numerosas otras personas, ya sea que participen de modo distinto en los tratamientos de salud, o desempeñen tareas meramente administrativas; este también es un terreno en que florecen las faltas de servicio. Los dos ámbitos más significativos en que se agrupan las faltas de servicio corresponden, por una parte, al de los cuidados brindados al paciente, incluidos los defectos de vigilancia y, por otra, a las gestiones administrativas del hospital.

\section{b.1.- La culpa en los cuidados del paciente.}

Las prestaciones sanitarias en que interviene personal no médico son de lo más variadas. Van desde la práctica de procedimientos auxiliares a la intervención del médico, como la realización de exámenes de salud o el suministro de algún medicamento (por ejemplo, mediante inyecciones) hasta el acompañamiento de los pacientes durante su hospitalización.

Algunas de estas tareas sólo pueden confiarse a determinados profesionales, caso en el cual la culpa depende de calificaciones relativamente similares a la culpa médica ${ }^{80}$ (aunque los deberes de estos profesionales no guarden comparación, en razón de su complejidad, con los deberes médicos). Así, hay falta de servicio si una matrona no valora adecuadamente el cuadro clínico de un neonato, como ocurre en Fuentes Figueroa. ${ }^{81}$

Sin embargo, fuera de esos casos, la falta de servicio en este

\footnotetext{
Rol N $12.486-2019$.

${ }^{78}$ Corte Suprema, 31 de julio de 2012, Rol № 9.140-2009.

${ }^{79}$ Corte Suprema, 3 de septiembre de 2015, Rol N 9.058-2015 (esterilización no consentida).

${ }^{80}$ Más allá de la medicina, el recurso a la idea de la lex artis o reglas o usos normativos del oficio es un rasgo común a los regímenes de responsabilidad por culpa en el ejercicio de actividades profesionales (de abogados, contadores, arquitectos, etc.). Cfr. BARros, cit. (n. 3), p. 104.

${ }^{81}$ Corte Suprema, 9 de enero de 2017, Rol №31.492-2016.
} 
campo viene determinada, en general, por la inobservancia de estándares prudenciales cuyo establecimiento no requiere de calificaciones técnicas complejas. Así, hay falta de servicio si durante las curaciones practicadas en tejidos sensibles de una paciente, una enfermera aplica agua hirviendo. ${ }^{82}$ Para la jurisprudencia, tampoco es dudoso que el traslado en camilla de un paciente debe llevarse a cabo en condiciones seguras, que impidan su caída. ${ }^{83}$ En muchos de estos casos el juicio de responsabilidad depende de la calificación de conductas más o menos sencillas a ojos de un profano, relativamente similares a las que pueden observarse en ámbitos de acción distintos de la salud pública.

\section{b.2.- En especial, los defectos de vigilancia}

Parte importante de estas faltas de servicio se verifican a propósito de la vigilancia de los pacientes y su estado de salud. Es deber del servicio, radicado en este personal no médico, monitorear más o menos permanentemente el estado del paciente, sea que éste haya sido hospitalizado o se encuentre de algún modo bajo el cuidado del establecimiento. Se ha fallado que las faltas de servicio por infracción a este deber de vigilancia pueden cometerse desde el ingreso del paciente al recinto hospitalario y aún antes de recibir atención. ${ }^{84}$ Con mayor razón, la insuficiente vigilancia de la evolución del paciente -por ejemplo, un neonato ${ }^{85}$ una parturienta ${ }^{86}$ o una persona que convalece de una intervención quirúrgica ${ }^{87}$ - configura una falta de servicio.

Los daños sufridos por pacientes internados en hospitales psiquiátricos podrían caber dentro de esta categoría, aunque, por la relativa complejidad de los cuidados que ahí se dispensan, merecen un análisis singular. En efecto, los deberes del establecimiento comprenden usualmente la custodia y vigilancia de estos pacientes, pero el cumplimiento de estas misiones se ve muchas veces dificultado por la voluntad de escapar de los internos o, incluso, sus tendencias suicidas. En la determinación del defecto de vigilancia inciden el cuadro del paciente y su historial, que contribuyen a precisar la previsibilidad

\footnotetext{
${ }^{82}$ Corte Suprema, 4 de septiembre de 2012, Rol No 8.044-2010.; la culpa se califica, discutiblemente, como falta personal, aunque el Estado (Hospital Naval de Talcahuano) responde igualmente.

${ }^{83} \mathrm{~V}$. nota 2.

${ }^{84}$ Corte Suprema, 25 de octubre de 2016, Rol N² 22.751-2015 (infarto sufrido en los alrededores de la sala de espera).

${ }^{85}$ Corte Suprema, 7 de noviembre de 2016, Rol N ${ }^{\circ} 52.870-2016$.

${ }^{86}$ Corte Suprema, 3 de enero de 2017, Rol N ${ }^{\circ} 47.886-2016$.

${ }^{87}$ Corte Suprema, 12 de marzo de 2018, Rol N 3.958-2017.
} 
del daño, así como los medios del hospital. Estos dos factores están relacionados. Por una parte, es inequívoco que la personalidad o patología del paciente psiquiátrico determina los deberes de servicio, que presentan notas singulares respecto de las prestaciones sanitarias más comunes ${ }^{88}$ Por eso mismo, el estándar exigible en la vigilancia de estos pacientes no puede ser idéntico en hospitales que cuenten con servicios especializados en el tratamiento psiquiátrico del que se espera de establecimientos comunes y corrientes. ${ }^{89}$

\section{c) Faltas en la gestión administrativa del hospital}

Adicionalmente, una proporción significativa de la falta de servicio de los establecimientos de salud proviene de irregularidades cometidas en el cumplimiento de misiones ajenas a los cuidados a los pacientes (aunque más o menos vinculadas con ellos) o bien a disfuncionamientos imputables globalmente a la organización del servicio. Por su similitud con otras hipótesis podría hablarse de faltas de servicio en la gestión administrativa del hospital, aunque sin duda su determinación no es ajena a consideraciones propiamente sanitarias.

\section{c.1.- Fallas humanas de gestión.}

Algunas faltas de servicio se refieren a la distribución del trabajo al interior del hospital. Por ejemplo, en el reciente caso Méndez Dabdub la responsabilidad arranca del hecho de que una matrona "interprete" (erróneamente) los resultados de un examen, lo que implica que personal no calificado aborde tareas propias de los médicos. ${ }^{90}$

\footnotetext{
${ }^{88}$ Así, en Medel Quezada, la Corte de Apelaciones de Valparaíso apunta a la insuficiencia de las medidas para evitar que un paciente saltara del tercer piso del hospital psiquiátrico, constitutiva de falta de servicio atendida la previsibilidad del daño. En palabras de la corte: “(...) otros pacientes ya habían usado ese medio (la ventana del tercer piso) para suicidarse, que Mario Hernán Tello habría manifestado sus intenciones suicidas e incluso habría sido visto encaramado en dicha ventana (...)". Corte de Apelaciones de Valparaíso, 15 de junio de 2005, Rol. № 917-2003, confirmada por Corte Suprema, 27 de septiembre de 2005, Rol No 3434-2005.

${ }^{89}$ Corte Suprema, 25 de julio de 2016, Rol № 1.511-2016 (suicidio de paciente herido, atendido de urgencia en hospital general). Cfr. también Corte Suprema, 2 de noviembre de 2017, Rol N 4.839 2017 (suicidio de paciente con sobredosis de fármacos, tratado sin sujeción al protocolo de atención psiquiátrica, en ausencia de síntomas de ideación suicida).

${ }^{90}$ Corte Suprema, 29 de junio de 2018, Rol №35.721-2017 (interpretación de exámenes y formulación de diagnóstico por una matrona). Adviértase que el caso se resuelve en aplicación de las normas del Código Civil, por entenderse que el establecimiento hospitalario, gestionado por una corporación municipal y no directamente por la municipalidad, se rige por el derecho privado. Con todo, el método de establecimiento de la culpa del establecimiento es por completo similar al de una falta de servicio
} 
También puede haberlas en el plano de la gestión de la atención de los usuarios. En Morales Gaete, por ejemplo, se incumple la orden de derivación de un paciente desde un hospital a otro, sin que el hospital derivado lo hubiera siquiera puesto en lista de espera, con el resultado de que no recibe las prestaciones que corresponde. ${ }^{91}$ El retraso en la práctica de una cirugía que no admite postergación también puede ser constitutivo de falta de servicio. ${ }^{92}$

Varios casos de falta de servicio corresponden a defectos en la custodia de objetos vinculados a prestaciones médicas, análogos a las faltas de vigilancia que se aprecian en la atención de pacientes o a otras culpas cometidas en la guarda de cosas. Entre otros, se han conocido casos de faltas de servicio correspondientes al extravío de un feto, ${ }^{93}$ de una biopsia, ${ }^{94}$ de la ficha clínica del paciente ${ }^{95}$ o de los resultados de un examen -así como, en general, varios casos de desórdenes en la entrega de exámenes. ${ }^{96} \mathrm{El}$ análisis de estos casos no presenta particularidades muy significativas frente a los defectos en la custodia de objetos, cometidos en servicios públicos distintos de los sanitarios.

\section{c.2.- La inadecuación de los medios.}

En el panorama general de las faltas de servicio cometidas en la gestión hospitalaria, cabe hacer un lugar aparte a aquellas consistentes en la deficiencia o insuficiencia de los medios con que cuenta el establecimiento. No es inusual que el origen de un accidente hospitalario se encuentre en una situación objetiva vinculada a la existencia o condición de los bienes materiales del establecimiento, ya sean sus instrumentos o insumos, o aun sus propias instalaciones. Sin duda, la condición objetiva de una cosa no puede per se calificarse como culpable; sin embargo, ella revela o puede revelar un cumplimiento defectuoso de las misiones del establecimiento

colectiva. Para un caso similar, Corte Suprema, 13 de abril de 2011, Rol N 1.093-2011. (extracción de sangre por un paramédico, sin idoneidad profesional relativa al procedimiento).

${ }^{91}$ Corte Suprema, 2 de marzo de 2017, Rol N 34.842-2016.

${ }_{92}$ Corte Suprema, 1 de julio de 2019, Rol No 9.041-2018.

${ }^{93}$ Corte Suprema, 29 de abril 2004, Rol N ${ }^{\circ} 4.212-2002$.

${ }^{94}$ Corte Suprema, 13 de enero de 2011, Rol No 363-2009.

${ }^{95}$ Corte Suprema, 28 de abril de 2014, Rol N².509-2014.

${ }^{96}$ Por ejemplo, Corte Suprema, 22 de septiembre de 2016, Rol N 9.481-2016 (caso del Hospital de Iquique, que omitió notificar los resultados de exámenes de VIH a unas 25 personas, entre otros la víctima). 
relativas a contar con un equipamiento acorde a sus funciones y capacidades. La jurisprudencia permite apreciar tres series de situaciones distintas:

\section{(i) Defectos del instrumental}

En Rojas Contreras la falta de servicio es reconocida por la utilización de instrumentos dentales de los que sale un líquido corrosivo en vez de agua. ${ }^{97}$ Tal vez la solución es extensible a otros casos en que el accidente se deba al mal estado de las cosas empleadas en la atención del paciente, como maquinaria o utensilios de uso médico, ${ }^{98}$ medicamentos, desinfectantes o productos sanguíneos o de otra índole, etc.

En estos casos los jueces no dudan demasiado en imponer la responsabilidad al hospital. Este mecanismo parece obedecer a una presunción de falta de servicio construida a partir del estado defectuoso del objeto: el mal estado revela que en la adquisición, elaboración o mantención de esos equipos o insumos se ha cometido una falta de servicio. Por cierto, para que la presunción opere se requiere que la culpa presunta haya podido estar dentro del ámbito de deberes del hospital. Es discutible que este criterio sea extensible al uso de productos médicos elaborados fuera del hospital y que no pueden ser inspeccionados previamente.

\section{(ii) Déficit del instrumental}

En Ponce Carrasco la circunstancia de que un tomógrafo se encuentre "descompuesto desde hacía ya varios días" impide la práctica de un scanner, lo cual es considerado como falta de servicio. ${ }^{99}$ Aquí el mal estado es causa de la indisponibilidad del equipo, lo que muestra la estrecha conexión entre defectos e insuficiencia del instrumental, o que contar con instrumentos defectuosos puede equivaler a no tenerlos. Sin duda, el papel causal de estas figuras es distinto, pues mientras el mal estado de una cosa suele ser causa directa del daño, la ausencia de materiales sólo impide su evitación.

Como ocurre en general en casos relativos a omisiones, en esta materia lo jurídicamente relevante consiste en determinar si algún estándar

\footnotetext{
${ }^{97}$ Corte Suprema, 19 de octubre de 2016, Rol N 49.707-2016.

${ }^{98}$ En un antiguo caso Cancino Rojas la responsabilidad es acogida, bajo el pretexto de negligencia del equipo médico, aparentemente en razón de la inoculación al paciente residuos provenientes del lavado de jeringas: Juzgado de Talca, 26 de mayo de 1989, Revista Ius et Praxis, 1996, n 2-1, pp. 125 y s., confirmada por Corte de Talca, 25 de septiembre de 1990, y Corte Suprema, 9 de mayo de 1991, Gaceta Jurídica, 1991, n 131, p. 78 y ss.

${ }^{99}$ Corte Suprema, 15 de mayo de 2012, Rol № 9.145-2009.
} 
normativo exige al hospital contar con esos equipos o insumos. ${ }^{100}$ En principio, el desajuste entre el equipamiento exigible y el realmente disponible puede revelar una mala organización, que es un tipo de falta de servicio. No obstante, como en todo orden de cosas, la falta de servicio no opera de modo automático cada vez que falta un equipo del hospital, pues hay que atender a las gestiones realizadas para repararlo, reemplazarlo o conseguir un equivalente.

Ahora bien, la responsabilidad no debe derivar en una estigmatización sistemática de los establecimientos con menor capacidad presupuestaria (que, para aquellos de dimensiones o complejidad más reducidas importaría una especie de culpa por existir). En cuanto la falta de servicio corresponde a una especie de culpa, una condición elemental de su procedencia consiste en que el servicio haya podido adecuar su comportamiento al estándar exigible. Por lo mismo, debería pensarse que la condición económica del hospital está asociada a los niveles de servicio que se le exigen; considerando que el sistema legal vigente categoriza los establecimientos grosso modo en función de su complejidad, ${ }^{101}$ a mayor complejidad deberían corresponder mayores medios y viceversa. En buenas cuentas, las definiciones sobre el equipamiento exigible de cada establecimiento hospitalario deberían derivar también de esa funcionalidad reconocida en consideración a su complejidad.

\section{(iii) El caso de las infecciones intrahospitalarias}

Un problema creciente para los hospitales consiste en enfrentar las infecciones nosocomiales, es decir, aquellas contraídas al interior del hospital, sin estar presentes o en incubación antes del ingreso del paciente. ¿Puede considerarse que los daños sufridos por infecciones hospitalarias se enfrenten con una lógica similar, como fruto del estado defectuoso de las instalaciones del hospital?

En Oviedo Pérez el servicio de salud se defendió alegando encontrarse en la imposibilidad de erradicar estas infecciones. ${ }^{102}$ El argumento supone

\footnotetext{
${ }^{100}$ Debe tenerse presente que los jueces no siempre se remiten a las fuentes normativas para establecer los instrumentos o equipos relevantes, lo que teóricamente podría provocar distorsiones en la forma de adjudicar el presupuesto. V. p. ej., Corte Suprema, 22 de noviembre de 2017, Rol N 35.184-2017 (elementos que permitan traslado de un menor después de operado).

${ }^{101}$ Cfr. nota 29.

${ }^{102}$ Esta parecía ser la solución a que propendía el fallo de la Corte de Apelaciones de Concepción, de 10 de agosto de 2000, Rol N¹.977-1999, al declarar que el hospital responde con independencia de
} 
en algún grado que el recinto hospitalario tiene por rasgo consustancial albergar ciertos factores patógenos que, ni aún con los mayores esfuerzos, no pueden ser eliminados. De ser efectivo este alegato, la responsabilidad operaría con prescindencia de los cuidados o precauciones tomados para evitar la materialización del daño, esto es, como una responsabilidad sin culpa, ajena al modelo de la falta de servicio. ${ }^{103}$

La jurisprudencia se ha mostrado reticente frente a este tipo de excusas, prefiriendo situarse sobre el terreno mejor conocido de la falta de servicio en las prestaciones sanitarias. Dado que el hospital debe prevenir la ocurrencia de estas infecciones, el contagio de los pacientes debe ser detectado y enfrentado a tiempo. De aquí que la presencia de estas infecciones configure, en el tratamiento jurisprudencial, una falta de servicio de vigilancia, ${ }^{104}$ de diagnóstico ${ }^{105} \mathrm{o}$ de tratamiento. ${ }^{106}$ En suma, en el estado actual del derecho se ha privado de especificidad al problema de las infecciones nosocomiales, lo cual podría ser discutible jurídica o políticamente. ${ }^{107}$

\section{CONCLUSIONES}

La principal conclusión que resulta de este estudio consiste en que el régimen de la falta de servicio se encuentra sólidamente arraigado en el ámbito de la responsabilidad hospitalaria. Si hubo un periodo de dispersión

sus esfuerzos. Sin embargo, el criterio fue desmentido por la Corte Suprema, 24 de enero de 2002, Rol N³.665-2000.

${ }^{103}$ Desde luego, aun en escenario de infección declarada, el servicio puede oponer otras excusas, como la ausencia de relación causal entre los defectos de asepsia y el estado de salud del paciente; cfr. Corte Suprema, 29 de junio de 2018, Rol N 34.225-2017.

${ }^{104}$ Corte Suprema, 6 de noviembre de 2017, Rol N 62.104-2016.

${ }^{105}$ Corte Suprema, 14 de julio de 2015, Rol N 4.156-2015 y Corte Suprema, 24 de enero de 2018, Rol No33.865-2017.

${ }^{106}$ Corte Suprema, 27 de febrero de 2018, Rol N²1.599-2017 (infección a raíz de la instalación fallida de un catéter).

${ }^{107}$ Esta solución es conservadora. Si es cierto que hay algo estadísticamente inevitable en las infecciones, entonces hay algo aleatorio en la materialización concreta de ese riesgo: cualquier persona corre un riesgo importante de infectarse al ingresar a un quirófano. Antes que una excusa, el argumento sugiere que es inaceptable que la entrada al hospital pueda generar consecuencias tan radicales. Siguiendo orientaciones del derecho comparado, es razonable que cargas públicas repartidas desigualmente se corrijan mediante una responsabilidad sin culpa. Con todo, dada la extensión previsible de un régimen de esta especie (que comprenda todos los hospitales públicos y quizá privados), y su impacto en las finanzas públicas, la cuestión debería discutirse a nivel legislativo. 
jurisprudencial en la materia, está superado: la falta de servicio no enfrenta la concurrencia de ningún otro régimen de responsabilidad. Esta apreciación no carece de interés, porque el terreno de la responsabilidad hospitalaria es extraordinariamente amplio; tanto las deficiencias de profesionales u otros agentes del hospital, como la gestión material del establecimiento están sujetos a un uniforme $\mathrm{y}$, por lo mismo versátil, régimen de responsabilidad por falta de servicio.

Sin duda, para propósitos didácticos o analíticos es útil anotar las principales categorías en que se reparten los accidentes más comunes en el hospital. Por la índole de cuestiones que plantean, la barrera entre actos médicos y los demás supuestos en que no intervienen los médicos subsiste como la principal distinción que domina la materia. Ahora bien, esa distinción no se traduce en regímenes diferenciados de responsabilidad. La diferencia entre un campo y otro no es decisiva, es decir, no implica un tratamiento más favorable o adverso respecto de ninguna de esas categorías de casos o de víctimas.

El apego persistente de la jurisprudencia al régimen de responsabilidad por falta de servicio revela que la garantía de intangibilidad del paciente está condicionada por una falla en la prestación hospitalaria. Es por eso que el sistema presenta, de un modo general, una similitud aparente con el derecho privado de la responsabilidad extracontractual (por culpa).

\section{BIBLIOGRAFÍA CITADA}

\section{a) Doctrina}

Barros Bourie, Enrique, Tratado de responsabilidad extracontractual, Editorial Jurídica Santiago, 2006.

CÁrdenas Villarreal, Hugo; Moreno Molinet, Jaime, Responsabilidad médica. Estándares jurisprudenciales de la falta de servicio, Legal Publishing, Santiago, 2011.

Cárdenas Villarreal, Hugo, "La legitimación pasiva de la administración médico sanitaria en la era de los establecimientos autogestionados en red", Revista Chilena de Derecho, 2018, Vol. 45, N².

Duez, Paul, La responsabilité de la puissance publique (en dehors du contrat), Dalloz, París, 1938, $2^{\mathrm{a}}$ ed.

Huepe Artigas, Fabián, "La falta de servicio en la responsabilidad sanitaria", en: Letelier, R. (coord.), La falta de servicio, Legal Publishing, Santiago, 2012. 
JÈzE, Gaston, "De la responsabilité pécuniaire des patrimoines administratifs au cas de faute personnelle", Revue du Droit Public, 1914.

Laubadère, André de; Venezia, Jean-Claude; Gaudemet, Yves, Traité de droit administratif, LGDJ, París, 1999, $15^{\text {a }}$ ed., T.I.

LONG, Marceau, "La responsabilité de l'administration pour les fautes personnelles commises par ses agents à l'occasion du service", Etudes et Documents du Conseil d'Etat, 1953.

Long, Marceau ; Weil, Prosper; Braibant, Guy; Delvolvé, Pierre; Genevois, Bruno, Les grands arrêts de la jurisprudence administrative, Dalloz, París, 1999, $12^{\mathrm{a}}$ ed.

Pierry Arrau, Pedro, "La falta de servicio en la actividad médica", Revista de Derecho del Consejo de Defensa del Estado,2003, № 8 .

Pizarro Wilson, Carlos, "Controversias jurisprudenciales de la responsabilidad de los servicios públicos de salud", Cuadernos de Análisis Jurídico, $2007, \mathrm{~N}^{\circ} 6$.

Pizarro Wilson, Carlos, La responsabilidad civil médica, Thomson Reuters, Santiago, 2017.

Silva Cimma, Enrique, Derecho administrativo chileno y comparado, T. IV ("El servicio público), Editorial Jurídica de Chile, Santiago, 1995.

Sото KLoss, Eduardo, "Falta de servicio ¿Régimen general de la responsabilidad del Estado/Administración en Chile? (El derecho ¿arte de magia?)", en Universidad Santo Tomás (eds.), La responsabilidad del Estado $\square$ Administración. Conferencias Santo Tomás de Aquino 2006, Ed. Andros, Santiago, 2006.

TOCORnal COOPer, Josefina, La responsabilidad de clínicas y hospitales, Legal Publishing, Santiago, 2014.

Valdivia Olivares, José Miguel, “Teoría del órgano y responsabilidad pública en la Ley de Bases de la Administración del Estado", Revista de Derecho (Valdivia), 2006, Vol. 19.

Valdivia Olivares, José Miguel, “¿Por qué es importante el fallo 'Promel' para el derecho público?”, Justicia Ambiental, 2009, №1.

Valdivia Olivares, José Miguel, "La culpa médica en la responsabilidad de los hospitales públicos”, Revista Médica de Chile, 2018, Vol. 146.

VÁsquez Rogat, Andrés. Responsabilidad del Estado por sus servicios de salud, Ed. Conosur, Santiago 1999.

b) Jurisprudencia nacional

Juzgado de Letras de Talca, 26 de mayo de 1989, Revista Ius et Praxis, 1996, 2-1, p. 125 y ss.

Corte de Apelaciones de Talca, 25 de septiembre de 1990, Gaceta Jurídica, 
$\mathrm{n}^{\circ} 131,1991$, p. 78 y ss.

Corte de Apelaciones de La Serena, 22 de noviembre de 1989, Rol 629. 1998.

Corte de Apelaciones de Valparaíso, 2 de septiembre de 1999, Rol 2.934-

Corte de Apelaciones de Concepción, de 10 de agosto de 2000, Rol 1.9771999.

Corte de Apelaciones de Valparaíso, 15 de junio de 2005, Rol. 917-2003.

Corte de Apelaciones de Rancagua, 31 de diciembre de 2010, Rol 471-2010.

Corte de Apelaciones de Talca, 4 de noviembre de 2016, Rol 1.223-2016.

Corte Suprema, 9 de mayo de 1991, Gaceta Jurídica, n 131, 1991, p. 78 y ss.

Corte Suprema, 10 de octubre de 1991, Rol 4944-1991.

Corte Suprema, 20 de junio de 1996, Rol 33.393-1995.

Corte Suprema, 24 de enero de 2002, Rol 3.665-2000.

Corte Suprema, 29 de abril de 2004, Rol 4.212-2002.

Corte Suprema, 27 de septiembre de 2005, Rol 3434-2005.

Corte Suprema, 31 de mayo de 2007, Rol 3174-2005.

Corte Suprema, 12 de junio de 2007, Rol 2.954-2006.

Corte Suprema, 21 de julio de 2009, Rol 2.849-2009.

Corte Suprema, 13 de enero de 2011, Rol 363-2009.

Corte Suprema, 14 de enero de 2011, Rol 7.919-2008.

Corte Suprema, 13 de abril de 2011, Rol 1.093-2011.

Corte Suprema, 23 de diciembre de 2011, Rol 6599-2009.

Corte Suprema, 15 de mayo de 2012, Rol 9.145-2009.

Corte Suprema, 31 de julio de 2012, Rol 9.140-2009.

Corte Suprema, 4 de septiembre de 2012, Rol 8.044-2010.

Corte Suprema, 5 de octubre de 2012, Rol 5.604-2010.

Corte Suprema, 6 de noviembre de 2012, Rol 1.013-2011

Corte Suprema, 6 de noviembre de 2012. Rol 5.417-2012.

Corte Suprema, 15 de noviembre de 2012, Rol 2.411-2012.

Corte Suprema, 30 de enero de 2014, Rol 9.006-2013.

Corte Suprema, 7 de abril de 2014, Rol 13.418-2013.

Corte Suprema, 28 de abril de 2014, Rol 2.509-2014.

Corte Suprema, 19 de mayo de 2015, Rol 4.388-2015.

Corte Suprema, 14 de julio de 2015, Rol 4.156-2015.

Corte Suprema, 3 de septiembre de 2015, Rol 9.058-2015.

Corte Suprema, 29 de enero de 2016, Rol 13.544-2015.

Corte Suprema, 23 de marzo de 2016, Rol 21.019-2015.

Corte Suprema, 16 de mayo de 2016, Rol 18.124-2015.

Corte Suprema, 19 de mayo de 2016, 32.268-2015.

Corte Suprema, 6 de junio de 2016, Rol 1.574-2016.

Corte Suprema, 28 de junio de 2016, Rol 34.161-2015. 
Corte Suprema, 25 de julio de 2016, Rol 1.511-2016.

Corte Suprema, 2 de agosto de 2016, Rol 16.002-2016.

Corte Suprema, 6 de septiembre de 2016, Rol 20.519-2016.

Corte Suprema, 14 de septiembre de 2016, Rol 35.566-2015.

Corte Suprema, 22 de septiembre de 2016, Rol 9.481-2016.

Corte Suprema, 7 de noviembre de 2016, Rol 52.870-2016.

Corte Suprema, 19 de octubre de 2016, Rol 49.707-2016.

Corte Suprema, 25 de octubre de 2016, Rol 22.751-2015.

Corte Suprema, 3 de enero de 2017, Rol 47.886-2016.

Corte Suprema, 9 de enero de 2017, Rol 31.492-2016.

Corte Suprema, 24 de enero de 2017, Rol 78.933-2016.

Corte Suprema, 2 de marzo de 2017, Rol 34.842-2016.

Corte Suprema, 25 de abril de 2017, Rol 34.836-2016.

Corte Suprema, 1 de junio de 2017, Rol 87.914-2016.

Corte Suprema, 4 de julio de 2017, Rol 95.114-2016.

Corte Suprema, 31 de julio de 2017, Rol 8.355-2017.

Corte Suprema, 8 de agosto de 2017, Rol 97.628-2016.

Corte Suprema, 14 de agosto de 2017, Rol 76.284-2016.

Corte Suprema, 14 de agosto de 2017, Rol 95.182-2016.

Corte Suprema, 2 de noviembre de 2017, Rol 4.839-2017.

Corte Suprema, 6 de noviembre de 2017, Rol 62.104-2016.

Corte Suprema, 9 de noviembre de 2017, Rol 1.745-2017.

Corte Suprema, 13 de noviembre de 2017, Rol 99.898-2016.

Corte Suprema, 14 de noviembre de 2017, Rol 83.397-2016.

Corte Suprema, 22 de noviembre de 2017, Rol 35.184-2017.

Corte Suprema, 26 de diciembre de 2017, Rol 11.526-2017.

Corte Suprema, 24 de enero de 2018, Rol 33.865-2017.

Corte Suprema, 21 de febrero de 2018, Rol 18.172-2017.

Corte Suprema, 27 de febrero de 2018, Rol 21.599-2017.

Corte Suprema, 12 de marzo de 2018, Rol 3.958-2017.

Corte Suprema, 18 de junio de 2018, Rol 6.549-2018.

Corte Suprema, 29 de junio de 2018, Rol 34.225-2017.

Corte Suprema, 29 de junio de 2018, Rol 35.721-2017.

Corte Suprema, 6 de julio de 2018, Rol 38.838-2017.

Corte Suprema, 3 de septiembre de 2018, Rol 40.328-2017.

Corte Suprema, 17 de junio de 2019, Rol N².468-2018.

Corte Suprema, 1 de julio de 2019, Rol N9.041-2018.

Corte Suprema, 1 de julio de 2019, Rol N7.755-2019.

Corte Suprema, 2 de julio de 2019, Rol N4.272-2019.

Corte Suprema, 22 de julio de 2019, Rol N¹2.486-2019. 
c) Jurisprudencia francesa

Conseil d'Etat, 18 de noviembre de 1949, Recueil Lebon, 1949, pp. 492 y ss. Conseil d'Etat, 26 de junio de 1959, Recueil Lebon, 1959, pp. 405 y ss.

Tribunal des Conflits, 5 de mayo de 1877, Recueil Lebon, 1877, pp. 437 y ss.

d) Normativa

Decreto con Fuerza de Ley $\mathrm{N}^{\circ} 1,1993$.

Decreto Ley N²763, 2006.

Historia de la Ley $n^{\circ} 18.575$, archivo .pdf, disponible en línea: https://www. bcn.cl/historiadelaley/nc/historia-de-la-ley/7579/ (fecha de visita: 16 de mayo de 2019).

Ley $\mathrm{N}^{\circ} 19.937,2004$.

Ley 19.966, 2004.

Ley $\mathrm{N}^{\circ} 18.575,1986$

Ley $\mathrm{N}^{\circ} 19.937,2004$.

Ley N²0.584, 2012. 